\title{
Seamus Heaney and the Emblems of Hope
}

\author{
Jessica Stephens
}

\section{(2) OpenEdition}

\section{Journals}

\section{Édition électronique}

URL : http://journals.openedition.org/etudesirlandaises/1689

DOI : 10.4000/etudesirlandaises. 1689

ISSN : 2259-8863

\section{Éditeur}

Presses universitaires de Caen

\section{Édition imprimée}

Date de publication : 30 septembre 2009

Pagination : 127-128

ISBN : 978-2-7535-0982-5

ISSN : 0183-973X

\section{Référence électronique}

Jessica Stephens, "Seamus Heaney and the Emblems of Hope », Études irlandaises [En ligne], 34.2 |

2009, mis en ligne le 30 juin 2011, consulté le 21 septembre 2020. URL : http://

journals.openedition.org/etudesirlandaises/1689; DOI : https://doi.org/10.4000/etudesirlandaises. 1689

Ce document a été généré automatiquement le 21 septembre 2020.

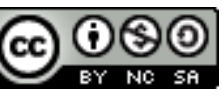

Études irlandaises est mise à disposition selon les termes de la Licence Creative Commons Attribution - Pas d'Utilisation Commerciale - Partage dans les Mêmes Conditions 4.0 International. 


\title{
Seamus Heaney and the Emblems of Hope
}

\author{
Jessica Stephens
}

\section{RÉFÉRENCE}

Karen Marguerite Moloney, Seamus Heaney and the Emblems of Hope, Columbia, University of Missouri Press, 2007, 249 pp., ISBN 978-0-8262-1744-8

Dans cet ouvrage paru en 2007, la poétesse Karen Marguerite Moloney s'intéresse à la tradition du «mariage sacré »: une déesse tellurique s'unit à un consort masculin et, par là même, lui octroie le droit de régner sur une terre et d'accéder au statut de roi à part entière. Des références au hieros gamos ("mariage sacré ») apparaissent déjà dans la littérature grecque et indienne, mais perdurent dans la littérature celte et plus précisément irlandaise. Si Karen Maloney évoque brièvement les traces historiques de ce rituel dont il est question dans un récit irlandais datant de 1187, elle examine les transformations du mythe au fil des siècles: en s'appuyant sur deux ouvrages - The Golden Bough de James Frazer et The White Goddess de Robert Graves -, elle balaye le champ de la littérature irlandaise. Des contes anciens relatent la transformation surnaturelle d'une vieille femme hideuse - la cailleach - en jeune femme à la beauté radieuse lorsque celle-ci est embrassée par un homme courtois qui, lui, reçoit un royaume en échange ( N Niall of the Nine Hostages» dans The Adventures of the Sons of Eochaid Muigmedon). Dans Buile Suibhne, le roi d'une province est transformé en oiseau ; il erre, à moitié fou, dans la nature irlandaise, tel Dionysos aux prises avec la Déesse... qui est aussi la Muse. Les événements historiques du XVII ${ }^{\mathrm{e}}$ et $\mathrm{du} \mathrm{XVIII}^{\mathrm{e}}$ siècles modifient progressivement la perception du mythe. Au XVIII ${ }^{\mathrm{e}}$ siècle, dans les poèmes de vision, les aislingí, la vieille femme caméléon est remplacée par une 'femme du ciel' éblouissante, la spéirbhean dont le compagnon s'est absenté. Ce personnage féminin canalise des émotions diverses, des préoccupations relevant du domaine politique, privé ou social ; les registres littéraires sont variés, comme dans The Midnight Court, poème comique écrit par Brian Merriman. Enfin Karen Moloney se penche sur la perception du 
" mariage sacré » et de la Déesse aux XIX ${ }^{e}$ et XX ${ }^{e}$ siècles - à travers certaines œuvres de Yeats, Joyce et Austin Clarke mais aussi d'écrivains très contemporains - hommes ou femmes; Thomas Kinsella, par exemple, voit dans sa confrontation avec la Déesse sous les traits de la spéirbhean ou bien de la cailleach - une étape dans l'acceptation de son ombre menant à une forme de régénération psychique. Eavan Boland, quant à elle, lie ce mythe à la situation actuelle de la femme irlandaise. Un peu comme Nuala Ní Dhómhnaill qui déplore la distinction faite entre l'image d'une femme désincarnée, associée à des principes abstraits - la liberté et la justice - et la situation bien réelle et quotidienne des femmes irlandaises.

2 Après cette vue d'ensemble, Moloney se tourne vers la poésie de Heaney à travers un choix de poèmes qu'elle étudie de manière très détaillée : les thèmes évoqués plus haut transparaissent mais sont réinterprétés et retravaillés. Plus que tout autre toutefois, Heaney explore la dimension politique de ce mythe. Dans "Ocean's Love to Ireland ", "The Guttural Muse », « Come to the Bower », mais aussi « Bone Dreams » et «A Drink of Water ", Heaney se penche sur le lien qui existe entre le roi et l'état du royaume qu'il gouverne, imagine une spéirbhean moins passive, explore la notion de transformation personnelle, associe l'eau et la déesse, se penche sur les valeurs véhiculées par la femme... 